\title{
Surveillance Technology in dementia care: implicit assumptions and unresolved tensions
}

\author{
Vermeer, $\mathrm{Y}^{1 \mathrm{a},}$ Higgs, $\mathrm{P}^{2 \mathrm{a}}$ and Charlesworth, $\mathrm{G}^{3 \mathrm{~b}}$ \\ a UCL, Faculty of Brain Sciences, Division of Psychiatry, Maple House,6th \\ Floor,149. Tottenham Court Rd, London W1T 7NF, \\ United Kingdom \\ ${ }^{b}$ UCL, Faculty of Brain Sciences, Department for Clinical, Education, and \\ Health Psychology, 1-19. Torrington Place, London, WC1E 7HB, United \\ Kingdom \\ ${ }^{1}$ Yvette Vermeer, y.vermeer@ucl.ac.uk, Early Stage Researcher, \\ 2Paul Higgs, p.higgs@ucl.ac.uk, Professor. \\ ${ }^{3}$ Georgina Charlesworth, G.charlesworth@ucl.ac.uk, Associate Professor, \\ Interdisciplinary Network for Dementia Using Current Technology [INDUCT]
}

Abstract. This paper examines the concept of "Surveillance Technology [ST]" as it is used in ageing and dementia research but which suffers from poor definition. We attempt to clarify this imprecision by contextualising a brief history of the development of ST and provide a summary of the research in this area. We contrast this with the responses provided by a public and patient involvement group of people living with a dementia diagnosis, or experience of supporting people with dementia. ST operates in multiple interacting ways, all of which need to be taken into account in research, public and policy debate. As a technology it is often seen as a way of assisting individuals and therefore classified as an Assistive Technology [AT]. However, the meaning of ST used in dementia care has pragmatic implications beyond the meeting of the needs for "safety and independence"; ideas which is often used to justify its use. We argue that there is need to interrogate the terms "Surveillance" and "Technology" more carefully if ST is to be considered as empowering for people with dementia. This tension is brought out in the accounts present in a group discussion on ST and its use. This paper argues that there needs to be an acknowledgement that the purposes of such technologies need to be regularly reviewed in order for society to keep up with the rapidly changing pace of technology and the changing needs of users. 
Keywords: surveillance, terminology, safety, technology, dementia, assistive, patient and public involvement.

\section{Introduction}

Public awareness of the challenges posed by an ageing population as well as the increasing demand for dementia care has become a mainstay of public debate [1, 2], as has the pressure placed on carers to manage risks of people living with dementia by taking appropriate safety measures [3]. This imperative is often interpreted as a need to find a technological solution to the problems of ageing [4]. Social policies and markets prioritise technological solutions [5]. In the field of dementia care technology is thought to delay institutionalisation; encourage older adults to remain in their own home [6]; to save costs [7] and alleviate the impact of the decreasing number of kin prepared to be full-time carers by reducing caregiver burden [8]. In other words, technology may empower carers and people with dementia [9]. For example, the NHS Long Term Plan recently reported the aim to empower people and to change their experience of health and care [10]. This includes home-based and wearable monitoring equipment which will predict and prevent incidents that would otherwise result in hospital admissions. The NHS will ensure that these technologies can be used as well as meet the needs from a range of people. The plan points out "This could include... a location tracker to provide freedom with security for someone with dementia" [10: 17].

Surveillance Technology [ST], is often the term used for products used to locate and 'track' the whereabouts of people with dementia [11]. ST is also seen as a technological product that can keep people with dementia independent and safe [3]. Not surprisingly, carers have expressed positive responses to such products [12]. ST is used in dementia care for various reasons. For example, carers want to diminish own stress by locating the person with dementia who wanders [13; 14]. Wandering is considered problematic as people with dementia might get lost and hurt [15]. There are various STs available to locate people for safety reasons. To illustrate, Global Positioning System [GPS] which can be incorporated, into the coat of a person with dementia, identifies the location and signals that position of a person from the device to a carer [16]. There are many different types of electronic devices with GPS. 'Track your Ltd.', [17] is a simple tracking devices connected to a phone, whilst 'Dementia buddy', [18] is a tracker with an 
alarm button connected to a support platform for a monthly fee [19]. Another example is an electronic bracelet that sends a tracking signal for programs such as 'Project Lifesaver', [20] connected to the police [3]. However, some ST have not been proven to be cost effective [14], have failed to reduce uptake of health and social care services [21] and have no effect on improving the quality of life (QOL) of people with dementia in their own homes [22].

\subsection{Terminology and definition}

ST has a terminology that keeps on expanding in society [23; 24]. Terms used for ST include: monitoring devices, personal and social alarms, telecare; electronic surveillance; information technology; tagging; tracking; wandering technologies; assisted living technologies; GPS device; ambient assisted living; Information and Communication Technology [ICT]; smart home technologies; and more [3; 12; 25-28]. It becomes problematic for both users and researchers when ST is inconsistently termed or defined as just technology [14]. For example, one study divided ICT into two functions of Assistive Technology (AT) and ST [29]. ATs were memory aids, calendars and devices for regulating kitchen equipment to compensate for cognitive defects. STs were safety alarms, electronic tagging devices and passive positioning systems such as mobile phones with GPS [29]. On the other hand, ST is often seen "as part of" [30]. For example, McCabe and Innes [12] described their GPS device for safer walking as AT. Another example is from Gibson and colleagues [31] and how carers and people with dementia made AT such as GPS devices work for them through personalisation, customisation and bricolage. The act of bricolage is combing household technologies with AT (e.g. placing duct tape over device buttons)[31].

The World Health Organisation (WHO) defines AT as: 'An umbrella term for any device or system that allows the individual to perform a task they would otherwise be unable to do or increases the ease and safety with which tasks can be performed' [2]. However, considering ST as part of AT may be a limited option [25]. For example the Cochrane review on AT products for memory support in dementia included tracking devices [32]. The authors had to use many search terms to find such devices and this resulted in the discovery of many false positives. They argue that there is a need for standardised terminology in order to better identify effectiveness studies for AT [32]. Similarly, Gibson and colleagues [31] acknowledged their limited 
wide definition of technology. Another study reported that a clear description of the meaning of video surveillance in practice would be useful. The authors themselves, however, used different terms throughout the article (e.g. surveillance, camera's, telecare, AT) [33]. Consequently, Tinker et al. [34] in their paper on terminology argue that ST should be more explicitly defined in order to implement changes in Gerontechnology.

It remains unclear, however, whether or not ST is part of AT. Studies show it operates in multiple interacting ways, which need to be taken into account in dementia studies as well as in public and policy debates. Terminological confusion may have a tendency to overlook tensions surrounding ST. To investigate such tensions, a suitable starting framework might be the description of ST as a monitoring system that allows carers to supervise a person with dementia for 24-hours [3]. This paper examines the tensions that exist within the literature of ST in dementia studies by providing a brief history of 'Surveillance' and 'Technology', by outlining some of the tensions that exist in this area, tensions which lead ST to be differentiated from AT. Lastly, we discuss the comments received about ST from a PPI group consisting of carers and people living with dementia.

\subsection{Tensions with ST}

Most discussion within this technological field focusses on how it is possible to surreptitiously use ST without fully engaging with the consent of the person with dementia; the justification being that increasing safety as overrides other ethical concerns [25]. For example, carers used bricolage to link tablets, webcams and home CCTV cameras to create a 'telecare' systems which over-rode any ethical concerns [31]. However, it has been pointed out that the use of technology often compromises autonomy and independence and promotes a false sense of safety [35]. It is also important to note that the belief that ST increases safety and reduces risks is asserted rather than being proven by research [25]. Niemeijer, [25: 124] has asked whether or not 'ST actually offer[s] more security'? ST can signal whether a fall happens; however, not it does not prevent the fall. A second tension that has received considerable critical attention is that technology such as ST should not be regarded as a substitute for human care $[25 ; 36]$. The perception of ST as the solution might undervalue carers and deplete the indispensable human 
contact that carers have with people with dementia [25]. A third tension featuring in much public and academic debate concerns the negative associations and moral implications of ST. The Oxford Dictionary describes surveillance as 'close observation, especially of a suspected person'. Gary Marx, [37], questioned if people with dementia are then seen as criminals. Family carers and people with dementia stressed the importance for consent to use ST by joint-decision making [12; 30]. For reasons that many concerns were reported about associating ST as a tool to manage people with dementia, children and criminals [12; 30; 38; 39]. Descriptions of ST as an malign tool [i.e. an Orwellian 'big brother watching you'] designed for social control is counterpoised to seeing it as a new technology that makes people secure [40]. Conversely, Judd [41] argues that the key to support people with dementia in order for them to have more control over their lives is to stress individual empowerment which valorises privacy and autonomy with less control from others.

\subsection{A brief history of ST}

To understand the role of ST in dementia it is necessary to look at the idea of the emergence of what has been described as a 'surveillance society' [42]. Studies outside the field of gerontology tend to think of surveillance as a constant feature of modern society. For example, Marx, [37], describes a generalised focus on discovering personal information through surveillance as a feature of contemporary society. In this view the collection of data and the surveillance of people becomes deeply enmeshed in a myriad of social practices [37]. Similarly, Foucault's [43] well known discussion of the idea of the 'Panopticon' in his work on prisons and its role in the construction of what he termed the 'docile body' [44] is another example of the role that surveillance is supposed to have in wider society. In 1957, the first globally orbiting satellites were tracked by surveillance on the ground [45]. In the 1960 s, electronic tagging and tracking was introduced as an alternative to custodial sentences [46].

Since that time the potential of surveillance has increased exponentially as technology has become more sophisticated and individuals have come to be more scrutinised in their everyday actions. Technology developed in one field rapidly extends to others. This has been as true in the field of social care 
as in other more obvious areas such as computer technology. Social care became an area ripe for technological intervention as the latter decades of the twentieth century saw an increase in the needs of an older population and a shift in the responsibility of providing care to the informal sector of family, friends, and neighbours [47]. This was accompanied by a discourse that the care provided by families was "good" whereas dependence on the state was "bad" [48].

From the 1980s onwards, two things occurred in the field of dementia research and technology. First, much academic research was conducted to see how these technological developments could be extended into the field of dementia care; however there was a dearth of take-up from designers and administrators [49]. Second, an impetus for developing the perfect ST also emerged leading to an ongoing perception that these products would meet a yet untapped market need which would both be profitable and cost effective $[50 ; 3]$. Later in the 1990s, technology was seen as a way of providing a variety of solutions for the welfare state in the United Kingdom (UK) [52; 53]. The National Health Service and Community Care Act 1990 [54] promised a 'mixed economy of welfare', focusing on market forces for the delivery of technological services [55]. A justification for this was for older individuals to be cared for in their own homes for as long as possible [54]. However, reforms in UK care and social services also led to a narrow market-orientated approach based on consumerism and to a degree "user involvement" or "user empowerment" [48]. This meant users got the option to choose between competing providers and deflect products which did not meet their needs [57]. User empowerment, however, was often confused with consumerism [48]. In a supermarket analogy it is consumerism which ensures that users have a wide choice in products and some safeguards as to safety and quality. Hereby a user who can choose between products in a supermarket becomes a consumer. This is because consumerism does not really consult consumers what types of products they want to have in the supermarket, nor does it involve consumers in the management of that supermarket. Therefore, in such a [super]market analogy the consumers remain powerless [48]. Meanwhile, carers started to be included in research and studies reported how they favoured tracking people with dementia, which started an ethical debate on the morality of surveillance [58]. Welsh and colleagues [58], argue that a Panopticon of an ultimate efficient prison 
system to use surveillance on prisoners, without considering them as humans, should never be allowed.

In the late 1990s specially adapted technological designs became standard features of mainstream products [59]. This transformation of adaptation into mainstream technology designs became widespread and contributed to a larger trend that is based on universal design $[59 ; 60]$. This led designers to base their ideas on previously perceived needs generated by a market which results in designs that are reflections of what has been previously created [61; 62]. For example, while cassette tapes were initially created to support talking books for the blind they became mainstream when used by the general public, yet later these tapes were specially repurposed for the blind [59]. This can also be seen with the "Wristcare" design for dementia care [61]. The designers had years of experience with developing safety phones and later adapted these phones by adding monitoring features. The Wristcare was designed in the light of the growing ageing population and was anticipated to have big potential for an ageing market. The monitoring safety phone market was also anticipated to open up a new market among younger consumers [61].

Consequently in the last few years the market for ST has expanded as the number of carers increased [3] but without any real development of what users needed. Other commentators, however, have argued that the surveillance market was in reality underdeveloped and is now just starting to use technologies to improve services for older adults [4]. Nonetheless, one major development was that in the UK it became common to monitor people with dementia [16], so that by 2010 there were 1.7 million telecare users in a market valued at $£ 106$ million [63;64]. Such devices are provided by local authorities, then private companies, followed by local and national technology resources [16]. This market is supported by the public sector with a small subsector selling directly to the public [16]. Policy makers continue to 'mainstream' ST within health-care given that there is a belief that it might alleviate the challenges of providing care without resort to institutional care and all of its costs [16]. Again, what is common to this process is that the development of ST has not addressed user involvement or indeed empowerment. However, as we show below, it is not that there is not a perspective from the users: it is just not heard or thought about. 


\section{Tensions about the use of ST: Reactions from PPI}

\subsection{Patient and public involvement}

There is an urgency to involve carers and people with dementia in patient and public involvement (PPI) [65]. Patient and public involvement is research being carried out "with" or "by" members of the public. For example, members of the public can offer advice or comment on research materials as they have personal knowledge and experience of the research topic and might provide a more general perspective [66]. However, PPI is often criticised as an exclusive and tokenistic practice involving a narrow group of experienced members [67]. INVOLVE, [2012] created briefing notes for researchers involving the public and NIHR, [68] recommended to continuously improve the development of PPI by beginning with diversity and inclusion [66; 68]. Despite these criticisms, PPI can improve the quality and relevance of research and lead to the empowerment of those members involved. This is particularly important for groups which have traditionally lacked power and voice, such as people living with dementia [65; 66]. This study is aligned to the larger Horizon 2020 funded, INDUCT programme (Interdisciplinary Network for Dementia Using Current Technology). INDUCT aims to improve technology and care for people with dementia. In addition, the specific aim of this study is to gain an understanding of the perspectives and needs of people with dementia and family caregivers towards surveillance technology. A decision was made to create a PPI group in the UK. The group was based on the guidelines from INVOLVE, [66]. A role description was disseminated on the NIHR Join Dementia Research website. The role description asked for members of the public with personal experience of living with dementia, who wanted to influence policy and research and were interested in sharing their thoughts on ST and empowerment. In addition, the role description outlined what was expected from the PPI members as research advisors.

Table 1. Inclusion criteria.

Inclusion criteria for PPI members 
The individual should have direct experience with dementia of being either:

- A person living with early set/ moderate dementia

- A [former] family carer supporting a loved one with dementia

- Live at home

- Have some knowledge of ST, or use ST

Table 1 describes the inclusion criteria for the research advisors. The PPI group included eight research advisors who are a family carer or themselves are living with dementia. The meeting took place in London in March 2018. During this meeting, the main author facilitated the discussion, one researcher had a supportive role and another researcher participated. Discussion included 'what is ST', 'can ST be empowering' and 'how would you categorise ST'. Hereby, the PPI group discussed ST and illustrates the existence of many tensions that are subsumed under the label of ST.

\subsection{What is ST?}

The PPI advisors spoke very passionately about surveillance. In particular, about the term surveillance and how it reminded them of police, prisoners, spies and the military. They emphasized that they feared this negative term might even put people off who want to use surveillance. The fear of how surveillance is used, as well as the tension surrounding its ethical implications was discussed. For example, people may not be aware of Facebook and CCTV monitoring them, with or without their consent. One advisor asked "am I actually in control or do third parties have access to my data? Another advisor commented with "surveillance is propensity for abuse". Therefore, the group agreed that regulations should be in introduced in relation to ST and the monitoring of people. One major reason given for this was disliking "big brother watching and collecting personal data". In spite of not liking the term, advisors felt they were all participating in surveillance in daily life without necessarily recognising it. Although there was a tendency to regard surveillance in a negative light, the group also discussed what benefits technology might bring about. 
A person with dementia thought that her latest Apple watch which was connected to an iPhone was helpful giving her a feeling of safety. The group discussed how the iPhone is not designed to keep an eye on people but can be used to do so with apps. Illustrating personalisation, customisation and bricolage of everyday devices for everyday purposes. In her situation, she reported that, everything was co-jointly discussed and decided upon with her partner. The group agreed that consent and joint-decision making is something that would enable people to accept the use of technology more. Furthermore, technology was seen as a helpful tool to support the giving of care. However, some advisors described their concerns with the improvement of technologies. One major reason was that improved camera's in the home might be used as an excuse to reduce human interaction. For example, one advisor mentioned concerns about "helpers only walk into the home when they spot the problem on camera". This led to the discussion of seeing ST not as a substitute of care. They agreed that technology usage should improve the QOL of people with dementia and support carers and not only have the purpose to reduce costs for the government. This led to talking about the tension of [not] increasing safety. The group questioned if technology prevents wandering and if carers then only react when a person has already fallen, which is not useful. Rather technology should enable people to do things they would not be able to do without it. However, some stressed again that the help from formal and family carers is essential. Consequently, they wondered if a passive tracker would be helpful at all.

\subsection{Can ST be empowering?}

The advisors expressed different opinions on the issue of empowerment. One advisor expressed the view that empowerment through the use of technology is the capacity to be able to do the things they would not be able to do without it. Others described empowerment as anything that creates, promotes or enhances autonomy, QOL, skills and the power to do what one wants. For example, one advisor reported "my [tracking app on the] iPhone gives me power to walk outside and my husband has the power to know that I am okay". The advisor described how this power made her feel empowered. However, some advisors felt that surveillance can quickly take away someone's power. The example of placing cameras in the home was described as taking away someone's power. One advisor asked "what 
happens when someone else has power over you". The discussion focused on the ethical implications of collecting personal data, which was considered disempowering. Descriptions were given of people in the later stages of dementia who had someone acting in their interest. Another example, giving another illustration of 'bricolage' one PPI member gave a description of using a home burglar alarm to provide an alert should his older relative with dementia open the front door. Carers discussed having the power to make decisions on behalf of the person with dementia. However, no consensus was reached on how society could ensure that this "power" is safely used. The group agreed that disempowerment is when someone else has power over you. Power should not be abused when making decisions on behalf of others and it was a priority that individual needs should be met.

\subsection{How would you categorise ST?}

Initially, the PPI group did not reach consensus when discussing what different categories there are of ST. Surveillance was sometimes termed as a "technology" or "concept". When the group questioned whether technology would fit their and other's individual needs, they decided upon the category of needs. For example, ST should be adaptable when dementia progresses to fit the needs of the persons using it. One carer described ST was initially easy to use. However, the person they supported started having troubles with the off button when the disease of dementia progressed. The advisors explained how they used existing technologies to support caregiving and other activities in daily life. Besides the earlier described iPhone, the advisors also mentioned products such as 'Amazon Echo' and 'Fitbit' which they used for surveillance. These products were discussed as "high-tech" and were perceived as a technology rather than just being forms of surveillance. Reasons given were that these high-tech products supported them to perform a task, or make certain tasks easier or safer. For example, the Amazon Echo played music whilst a timer was set for the stove.

Another topic was that of the effect of using ST. The group questioned what the purpose of ST should be and described that it should enable people to find their way home, or enable someone to find them. Again, the tension between increasing safety and independence emerged from this discussion. This category was discussed conjointly in terms of the reliability of the 
product; for example, batteries going low in times of need was an important issue. Given this point, the group agreed that ST is not just "Technology" as people are also involved in the practice of surveillance. For example, neighbours and carers checking in on a person living with dementia. In this case, advisors said it was important to leave the "technology" out of "surveillance technology". The importance of the role of carers was emphasized again and it was agreed that technology is just a support tool. Technology is considered to be an expensive tool for some and the focus should be on investing in healthcare instead.

\section{Discussion}

In this paper we examined theoretical attempts to define and describe ST which resulted in three tensions. ST might (not) 1) increase safety, 2) be a substitute for care, 3) have ethical implications. We followed this with an exploration of the concept of "Surveillance Technology" and what it means to people living with dementia and carers. The PPI group had an immersive understanding of ST which brought out some of the tensions implicit in the technology; ones that are rarely alluded to in the literature.

The PPI's intertwined discussion concurs with literature about the three tensions surrounding ST. The group discussed that ST can promote a false sense of safety by its passive use similar to Schulz et al. [35]. Furthermore, the PPI group questioned whether ST prevents wandering and falls corresponding with Niemeijer [25]. The group also discussed safety and how consent and joint-decision making is essential similar to previous studies [12; 30]. In addition, the group discussed the ethical implications of ST collecting data and how this can be disempowering. The PPI expressed how "Big Brother" (e.g. Facebook, CCTV) collects their data and hereby had power over them by dishonoring their privacy and autonomy. This contrasts with Judd's [41] argument to support people with dementia and to stress individual empowerment.

In line with the literature, the group describes that ST may not reduce costs, improve QOL and alleviate carers [7; 8; 22]. Rather, ST is just a supplement and instead they believed that more investment is needed in healthcare. Other similarities with the literature found that users associated ST with prisons $[12 ; 30]$ and that all of society is involved of data collection and 
categorization of people [37]. This might explain why the group termed surveillance as technology yet, sometimes stressed the importance of 'surveillance' as a separate concept. When discussing this, we have to be aware that definitions are often bound by those making them. We see differences from those in the industry and those actually using it. This may mean that the unproblematic adoption of such technologies may well be disempowering as well as being unresponsive to the needs of the users.

\subsection{Leave the "technology" out of "surveillance technology"}

It therefore might be helpful to distinguish between "Technology" and "Surveillance". Technology is something that responds to a need as shown by the advisor's use of existing "High-tech" products for various purposes. These technologies might then be placed within AT as they allowed individuals to perform tasks with ease and safety. Surveillance, on the other hand has a more specific purpose. A previous study found that simple lowtech trackers were sold to track not only people with dementia, but also dogs and prisoners [68]. Companies are looking for a market and surveillance is what the market offers for dementia [61]. If we use the supermarket analogy again it becomes noticeable that the ideology continues to be that dependence on the state is bad - and that families purchasing "surveillance products" is good [48]. However, literature and the PPI group described how low-tech products might not meet individual needs which creates tension. Within this user empowerment, which is confused with consumerism, consumers remain powerless, when surveillance is done to people anyway or others can take away our power quickly. That is, the PPI group emphasized that surveillance is done to persons without asking and operates outside users. Hereby the question shifts from "is surveillance part of AT?" to "is it part of a market ideology"? As regards AT's terminology [2], the anxieties people have about what surveillance means, as well as how does it serve the purpose of supporting people, seems to suggest that it is the opposite from AT. When people see 'Surveillance' as not increasing safety or reducing costs it is viewed as unhelpful. This negative assessment has more to do with 'big brother' than with technology itself. For ST to be empowering in the field of dementia care: we need to address the intentions that can emerge from the term ST. The difference between ST and AT is that surveillance is done to people whilst high-technology as part of AT, aims to supports people in their daily activities. Therefore, surveillance should be 
differentiated from AT and its positioning should be re-oriented to keep up with the rapidly changing nature of what is possible with technology and how this meets the needs of its users.

We would argue that part of the tension that surrounds ST is that we need to move beyond the idea that consuming ST will empower people with dementia and their carers. Instead of consumerism the focus should be on empowerment. That it has been missing from the debate, other than in the form of framing aspirations, is an indictment of the shift away from the users and towards something that has a more unconcerned set of priorities. In conclusion we think that is important for gerontologists to become clearer about the implicit assumptions and unstated tensions that exist in the field of ST if only to ensure that such technologies do not lead to the persistence of exclusionary practices in the care of people with dementia.

\section{$4 \quad$ References}

1. Alzheimer's disease International and World Health Organization. Dementia: a public health priority (2012). WHO at http://www.who.int/mental_health/ publications/dementia_report_2012, last accessed 19/1/2017.

2. WHO Centre for Health Development. A glossary of terms for community health care and services for older persons (2004). http://www.who.int/iris/handle/10665/68896, last accessed 5/5/2018.

3. Kenner, A. M. Securing the elderly body: Dementia, surveillance, and the politics of "Aging in place", Surveillance and Society, 5, 3, 252-69 (2008)

4. Sixsmith, A. New technologies to support independent living and quality of life for people with dementia, Alzheimer's Care Today, 7, 3, 194-202 (2006)

5. Kubitschke, L. Müller, S. Gareis, K. Frenzel-Erkert, U. Lull, F. Cullen, K. Delaney, S. Dolphin, C. Wynne, R. and Rauhala, M. ICT and Ageing: European study on users, markets and technologies-Final report (2010) Final Report at www.ict-ageing.eu, last accessed 7/1/ 2017. 
6. Brittain, K. Corner, L. Robinson, L. and Bond, J. Ageing in place and technologies of place: The lived experience of people with dementia in changing social, physical and technological environments, Sociology of Health and Illness, 32, 2, 272-87 (2010)

7. Duff, P. and Dolphin, C. Cost-benefit analysis of assistive technology to support independence for people with dementia-Part 2: Results from employing the ENABLE cost-benefit model in practice. Technology and disability, 19, 2, 3, 79-90 (2007)

8. McHugh, J. Wherton, J. Prendergast, D. and Lawlor, B. Identifying opportunities for supporting caregivers of persons with dementia through information and communication technology. Gerontechnology, $10,4,220-30$ (2012)

9. Kenigsberg, P.A. Aquino. J.P, Bérard. A, Brémond, F. Charras, K. Dening, T. Droës, R.M. Gzil, F. Hicks, B. Innes, A. Nguyen, Nygård, L. Pino, M. Sacco, G. Salmon, E. Van der Roest, H. Villet, H. Villez, M. Robert, P. and Manera, V. Assistive technologies to address capabilities of people with dementia: From research to practice, Dementia, 18, 4, 1-28 (2017)

10. Department of Health and Social Care. The NHS Long Term Plan (2019). https://www.gov.uk/government/news/nhs-long-term-plan-launched, last accessed 14/2/ 2019.

11. Landau, R. and Werner, S. Ethical aspects of using GPS for tracking people with dementia: recommendations for practice, International Psychogeriatrics, 24, 3, 358-66 (2012)

12. McCabe, L. and Innes, A. Supporting safe walking for people with dementia: User participation in the development of new technology, Gerontechnology, 12, 1, 4-15 (2013)

13. Landau, R. Auslander, G. K. Werner, S. Shoval, N. and Heinik, J. Families' and professional caregivers' views of using advanced technology to track people with dementia. Qualitative health research, 20, 3, 409-19 (2010)

14. Topo, P. Technology studies to meet the needs of people with dementia and their caregivers a literature review, Journal of Applied Gerontology, 28, 1, 5-37 (2009) 
15. McGilton, K. Rivera, T. and Dawson, P. Can we help persons with dementia find their way in a new environment?, Aging and Mental Health, 7, 5, 363-71 (2003)

16. Gibson, G. Newton, L. Pritchard, G. Finch, T. Brittain, K. and Robinson, L. The provision of assistive technology products and services for people with dementia in the United Kingdom, Dementia, 15, 4, 681-701 (2016)

17. Track your Ltd. Track your. (2013) Available online at: http://www.trackyour.co.uk/, last accessed 8/1/2017.

18. Dementia buddy. Dementia Buddy, Dementia Buddy we care because you care (2016) http://dementiabuddy.co.uk/, last accessed 9/1/ 2017.

19. Wan, L. Müller, C. Randall, D. and Wulf, V. Design of A GPS Monitoring System for Dementia Care and its Challenges in Academia-Industry Project, ACM Transactions on Computer-Human Interaction, 23, 5, 1-36 (2016)

20. Project Lifesaver. 2007. Available online at: Project Lifesaver, http://www.projectlifesaver.org/site/, last accessed 21/10/2017.

21. Steventon, A. Bardsley, M. Billings, J. Dixon, J. Doll, H. Beynon, M. Hirani, S. Cartwright, M. Rixon, L. Knapp, M. Henderson, C. Rogers, A. Hendy, J. Fitzpatrick, R. Newman, S. Effect of telecare on use of health and social care services: Findings from the Whole Systems Demonstrator cluster randomised trial, Age and Ageing, 42, 4, 501-8 (2013)

22. Cartwright, M. Hirani, S. P. Rixon, L. Beynon, M. Doll, H. Bower, P. and Rogers, A. Effect of telehealth on quality of life and psychological outcomes over 12 months (Whole Systems Demonstrator telehealth questionnaire study): nested study of patient reported outcomes in a pragmatic, cluster randomised controlled trial, BMJ, 346, 653 (2013)

23. Berridge, C. Furseth, P. I. Cuthbertson, R. and Demello, S. TechnologyBased Innovation for Independent Living: Policy and Innovation in the United Kingdom, Scandinavia, and the United States. Journal of Aging and Social Policy, 26, July, 37-41 (2014)

24. Lyon, D. Surveillance society: Monitoring everyday life. Open University Press. Buckingham and Philadelphia (2001) 
25. Niemeijer, A.R. 'Exploring good care with surveillance technology in residential care for vulnerable people', VU University Press. Amsterdam (2015)

26. Rialle, V. Ollivet, C. Guigui, C. and Hervé, C. What do family caregivers of Alzheimer's disease patients' desire in smart home technologies? Contrasted results of a wide survey, Methods of information in medicine, 1, 1, 63-69 (2009)

27. Sixsmith, A. Technology and the challenge of aging. in Gutman, G. (ed.), Technologies for Active Aging, MA, Springer, Boston New York, 7-25 (2013)

28. Te Boekhorst, S. Depla, M. F. I. A. Francke, A. L. Twisk, J. W. R. Zwijsen, S. A. and Hertogh, C.M.P.M. Quality of life of nursing-home residents with dementia subject to surveillance technology versus physical restraints: an explorative study, International Journal of Geriatric Psychiatry, 28, 4, 356-63 (2013)

29. Olsson, A. Engström, M. Skovdahl, K. and Lampic, C. My, your and our needs for safety and security: Relatives' reflections on using information and communication technology in dementia care, Scandinavian Journal of Caring Sciences, 26, 1, 104-12 (2012)

30. Robinson, L. Hutchings, D. Corner, L. Finch, T. Hughes, J. Brittain, K. and Bond, J. Balancing rights and risks: Conflicting perspectives in the management of wandering in dementia, Health, Risk and Society, 9, 4, 389-406 (2007)

31. Gibson, G. Dickinson, C. Brittain, K. and Robinson, L. Personalisation, customisation and bricolage: how people with dementia and their families make assistive technology work for them, Ageing and Society, 118 (2018)

32. Van der Roest, H. G. Wenborn, J. Pastink, C. Dröes, R. M. and Orrell, M. Assistive technology for memory support in dementia, Cochrane Database of Systematic Reviews, 6 (2017)

33. Mulvenna, M. Hutton, A. Coates, V. Martin, S. Todd, S. Bond, R. and Moorhead, A. Views of Caregivers on the Ethics of Assistive Technology 
Used for Home Surveillance of People Living with Dementia, Neuroethics, 10, 2, 255-66 (2017)

34. Tinker, A. Fozard, James, L. Kearns, W. Mihailidis, A. Atoyebi, O. Bailey, A. Bet, P. Lapierre, N. Neubauer, N. Roque, N. Vermeer, Y. and Taipale, V. Twelve years of ISG masterclasses: Past, present, and future, Gerontechnology Journal, 17, 4, 232-37 (2018)

35. Schulz, R. Wahl, H. W. Matthews, J. T. De Vito Dabbs, A. Beach, S. R. and Czaja, S. J. Advancing the aging and technology agenda in gerontology, Gerontologist, 55, 5, 724-34 (2015)

36. Cahill, S. Macijauskiene, J. Nygård, A. M. Faulkner, J. P. and Hagen, I. Technology in dementia care. Technology and Disability, 19, (2,3), 55-60 (2007)

37. Marx, G.T. What's New About the" New Surveillance"? Classifying for Change and Continuity, Surveillance and Society, 1, 1, 9-29 (2002)

38. Katz, C. The state goes home: Local hypervigilance of children and the global retreat from social reproduction, in Monahan, T. (ed.), Surveillance and Security: Technological Politics and Power in Everyday (2006)

39. Monahan, T. and Wall, T. Somatic surveillance: Corporeal control through information networks. Surveillance and Society, 4, 3, 154-73 (2006)

40. Percival, J. and Hanson, J. Big brother or brave new world? Telecare and its implications for older people's independence and social inclusion, Critical Social Policy, 26, 4, 888-909 (2006)

41. Judd, S. Part four Interventions: Technology, in Marshall, M. (ed.), State of the Art in Dementia Care, Centre for Policy on Ageing. London. (1997)

42. Lyon, D. The electronic eye: The rise of surveillance society, University of Minnesota Press. Minneapolis. (1994)

43. Foucault, M. Discipline and Punish: The Birth of the Prison, (Sheridan, A. Ed. Translated.), Second vintage books edition. May 1995. Random House, INC. New York (1977)

44. Caluya, G. The Post-Panoptic Society? Reassessing Foucault in Surveillance Studies. Social identities. 16, 5, 621-33 (2010) 
45. Meyer, A. D. GPS Declassified : From Smart Bombs to Smartphones by Richard D. Easton and Eric F. Frazier. Technology and Culture, 57, 1, 27678 (2016)

46. Gable, R. Left to their own devices: should manufacturers of offender monitoring equipment be liable for design defect, Journal of law, technology and policy, 333-62 (2009)

47. Gray, A. Normand, C. and Whelan, A. Care in the community : a study of services and costs in six districts (1988) https://ideas.repec.org/p/chy/respap/6cheop.html, last accessed 9/1/ 2019.

48. Barnes, M. and Walker, A. Consumerism versus empowerment: A principled approach to the involvement of older service users, Policy and Politics, 24, 4, 375-93 (1996)

49. Day, K. Carreon, D. and Stump, C. The therapeutic design of environments for people with dementia a review of the empirical research. The Gerontologist, 40, 3, 397-416 (2000)

50. Algase, D. L. Beck, C. Kolanowski, A. Whall, A. Berent, S. Richards, K. and Beattie, E. Need-driven dementia-compromised behavior: An alternative view of disruptive behavior, American Journal of Alzheimer's Disease and Other Dementias, 11, 6, 10-19 (1996)

51. National Health Service and Community Care Act 1990. Statutory Instruments. No. 1329 (C.37). National Health Service, UK, Wales, Scotland (1990)

52. Henman, P. and Adler, M. Information technology and the governance of social security, Critical Social Policy, 23, 2, 139-64 (2003)

53. Hudson, J. E-galitarianism? The information society and New Labour's repositioning of welfare, Critical Social Policy, 23, 2, 268-90 (2003)

54. Phillipson, C. Reconstructing Old Age: New Agendas in Social Theory and Practice, SAGE. London (1998)

55. National Institute for Health Research. Help at Home - Use of assistive technology for older people. NIHR Dissemination Centre (2018) 
https://www.dc.nihr.ac.uk/themed-reviews/Help-at-home-WEB.pdf, last accessed 20/1/ 2018.

56. Means, R. and Smith, R. Community care. Macmillan, Basingstoke (1994).

57. Welsh, S. Hassiotis, A. O'mahoney, G. and Deahl, M. Big brother is watching you--the ethical implications of electronic surveillance measures in the elderly with dementia and in adults with learning difficulties. Aging and mental health, 7, 5, 372-75 (2003)

58. Cook. M. and Hussey. A. Assistive technologies: principles and practice, Baltimore, Mosby (2002)

59. Newell, A. F. Design and the digital divide: insights from 40 years in computer support for older and disabled people. Synthesis Lectures on Assistive, Rehabilitative, and Health-Preserving Technologies, 1, 1, 1-195 (2011)

60. Hyysalo, S. Representations of use and practice-bound imaginaries in automating the safety of the elderly, Social Studies of Science, 36, 4, 599-626 (2006)

61. Strickfaden, M. and Heylighen, A. 2009. Who are they? Student Voices about the 'Other', Proceedings of the Include 2009. Helen Hamlyn Centre RCA, London

62. Deloitte. 2012. Primary care: Working differently. Telecare and Telehealth - A game changer for health and social care. https://www2.deloitte.com/uk/en/pages/life-sciences-andhealthcare/articles/telecare-and-telehealth.html, last accessed 9/1/ 2017.

63. Goodwin, N. 2010. The state of telehealth and telecare in the UK: prospects for integrated care. Journal of Integrated Care, 18, 6, 3-10

64. Brooks, J. Gridley, K. and Savitchm N. 2017. Removing the 'gag': involving people with dementia in research as advisers and participants. Social Research Practice, 3-14. Issue 3 - Winter 2016/2017

65. INVOLVE. N.I.H.R. 2012. Briefing notes for researchers: involving the public in NHS, public health and social care research. UK: INVOLVE Eastleigh. 
66. Ocloo, J., \& Matthews, R. 2016. From tokenism to empowerment: progressing patient and public involvement in healthcare improvement. BMJ Qual Saf, 25(8), 626-632.

67. NIHR. 2015. Going the extra mile: improving the nation's health and wellbeing through public involvement in research. London: NIHR.

68. Vermeer, Y. Higgs, P. and Charlesworth, G. 2018. Marketing of surveillance technology in three ageing countries, Quality in Ageing and Older Adults, Advance Access published 2018 